\title{
Long term effects of alumina on components of bronchoalveolar lavage fluid from rats
}

\author{
Göran Tornling, Eleonora Blaschke, Anders Eklund
}

\begin{abstract}
Significant differences in several components of bronchoalveolar lavage fluid (BAL fluid) have previously been reported in aluminium potroom workers compared with controls. The present paper describes the long term effects in rats of one time exposure to potroom aluminium oxide without fluorides (primary alumina (PA)) or with adsorbed fluorides (secondary alumina (SA) ) on components of BAL fluid. Alumina dust (40 $\mathrm{mg}$ ) suspended in saline was instilled intracheally; controls received saline. Bronchoalveolar lavage (BAL) was performed one, four, and 12 months after exposure. The number of cells in BAL fluid was increased significantly $(p<0.05)$ by SA but not PA. The increase was mainly macrophages, but the concentrations of neutrophils also increased about 10-fold one and 12 months after exposure. Although albumin and hyaluronan concentrations did not differ from those of controls, fibronectin concentrations were significantly $(p<0.001)$ increased one year after exposure both in PA exposed and SA exposed rats. The results indicate that SA, possibly because of adhered fluorides, induces early changes in alveolar cell populations including persistent neutrophilia. These cellular changes may have a destructive effect. The late pronounced increase of fibronectin in both PA and SA exposed rats indicates a delayed effect of alumina on the extracellular matrix.
\end{abstract}

(British Journal of Industrial Medicine 1993;50:172-175)

According to the review by Abramson et al ${ }^{1}$ aluminium reduction plant employees may develop an asthmatic syndrome, chronic obstructive lung disease, lung cancer, or pulmonary fibrosis. More recent reports, however, have failed to find clinical and

Department of Thoracic Medicine

G Tornling, A Eklund

Department of Clinical Chemistry, Karolinska Hospital, Stockholm, Sweden E Blaschke physiological signs of significantly impaired lung function in such workers. ${ }^{1-3}$ Potroom workers are exposed to two kinds of dust particles; "pure" alumina (aluminium oxide, $\mathrm{Al}_{2} \mathrm{O}_{3}$ ) and alumina with adhered gases, mainly fluorides. It is generally believed that pulmonary fibrosis is caused by the aluminium oxide, whereas potroom asthma has been attributed to irritants other than alumina such as fluorides. ${ }^{14}$

Early histopathological studies on alumina exposed rats (see review ${ }^{5}$ have shown that only the intratracheal instillation of reactive transitional alumina and high surface area alumina induced a fibronodular response. No clear cut fibrogenic effect was produced by "industrial" alumina. The BAL fluid response of alumina exposed rats was an early, and rapidly receding, increase in macrophages, lymphocytes, and polymorphonuclear cells, ${ }^{67}$ total protein concentration, and activity of cytolytic enzymes. ${ }^{7}$ Histologically, a transitional granulomatosis but no fibrosis was found. ${ }^{6}$ In vitro, crystalline particulate aluminium hydroxide showed no harmful effects on macrophages and fibroblasts. ${ }^{8}$

Using BAL for the examination of aluminium potroom workers, we have reported ${ }^{9}$ significant changes in several components compared with controls despite an absence of clinical symptoms. Thus it seemed that even mild prolonged exposure to pollutants in the potrooms may affect the alveolar environment. The findings prompted our present study on the long term effects of specific industrial samples of alumina in rats. To detect the possible influence of fluoride, effects of potroom aluminium oxide without (primary alumina (PA) ) and with adsorbed fluorides (secondary alumina (SA)) were compared. Besides markers of inflammatory alveolar reactions, two soluble components of the extracellular matrix were measured to trace possible fibrogenic effects.

\section{Methods}

CHARACTERISATION OF ALUMINA DUST

The raw material for the production of metallic aluminium, alumina (aluminium oxide, $\mathrm{Al}_{2} \mathrm{O}_{3}$ ), is purchased from various producers. In the present study, it was primary alumina (PA). The major part of this alumina is used to purify gases formed from 
fluorides during the electrolysis. After the adsorption of fluorides to alumina, the product designated as secondary alumina (SA) is introduced into the electrolytic pots and converted to metallic aluminium. This SA corresponds to the "fluoride recovery alumina" discussed by Lie and Eduard. ${ }^{4}$

Electron microscopical analysis showed that the mean particle size of PA dust was $4.37 \mu \mathrm{m}$ (SD $2.08 \mu \mathrm{m}$, median $3.54 \mu \mathrm{m}$ ), whereas the mean particle size of SA was $5.51 \mu \mathrm{m}$ (SD $2.29 \mu \mathrm{m}$, median $4.18 \mu \mathrm{m}) ; 78 \%$ of the PA and $66 \%$ of the SA had a particle size of less than $6.4 \mu \mathrm{m}$. The specific area of alumina dust was $45 \mathrm{~m}^{2} / \mathrm{g}$. Crystallographic analysis showed that the PA contained 75-80\% $\gamma-\mathrm{Al}_{2} \mathrm{O}_{3}$ and $20-25 \% \alpha-\mathrm{Al}_{2} \mathrm{O}_{3}$, the SA 70-75\% $\gamma-\mathrm{Al}_{2} \mathrm{O}_{3}$ and 25$30 \% \alpha-\mathrm{Al}_{2} \mathrm{O}_{3}$. The concentrations of $\delta, \kappa$ and $\theta-\mathrm{Al}_{2} \mathrm{O}_{3}$ were low. The SA also contained a small number of aluminium oxide fibres $0.05 \mu \mathrm{m}$ wide and $1-3 \mu \mathrm{m}$ long. The fluoride content of the SA was 1-2\%. Main impurities (maximum values) were: $\mathrm{Na}_{2} \mathrm{O} \mathbf{0} \cdot \mathbf{7 0} \%$, $\mathrm{CaO} 0.07 \%, \mathrm{SiO}_{2} 0.025 \%, \mathrm{Fe}_{2} \mathrm{O}_{3} 0.025 \%, \mathrm{ZnO}$ $0.01 \%$, and $\mathrm{Ga}_{2} \mathrm{O}_{3} 0.01 \%$; SA contains usually more impurities than PA.

\section{EXPERIMENTAL DESIGN}

Fifty nine Sprague Dawley rats with an initial weight of $200 \mathrm{~g}$ were used. They were divided into three groups and instilled with suspensions of PA $(\mathrm{n}=21), \mathrm{SA}(\mathrm{n}=21)$, and saline $(\mathrm{n}=17)$ respectively. The rats were kept in litters of at most four animals and food and fluid were unlimited. They were killed one, four, and 12 months after instillation. The study was approved by the ethics committee for animal experiments.

\section{INTRATRACHEAL INSTILLATION}

Under light ether anaesthesia a cannula was passed through the mouth into the trachea via the larynx with the rat fixed in a semiupright position. The alumina sample $(40 \mathrm{mg}$ ) was suspended in $0.5 \mathrm{ml}$ saline and rapidly injected into the trachea.

\section{BRONCHOALVEOLAR LAVAGE}

Lavage was performed as previously described. ${ }^{10}$ Briefly, the animals were killed with ether and the trachea was cannulated. Hank's balanced salt solution at $37^{\circ} \mathrm{C}$ was infused into the lungs in aliquots of $5 \mathrm{ml}$ at hydrostatic pressure of $20 \mathrm{~cm} \mathrm{H}_{2} \mathrm{O}$. After three minutes the fluid was drained by gravity into a siliconised tube placed on ice. The lavage procedure was repeated 10 times. The recovery of the instilled fluid did not differ between the controls (mean $89 \%$, SD $10 \%, n=17$ ) and alumina exposed rats (mean $92 \%$, SD $5 \%, n=42$ ) at any time after the instillation. Cell viability, determined by Trypan blue exclusion, did not differ between the controls (mean $95 \%$, SD $5 \%$ ) and alumina exposed rats (mean $94 \%$, SD $8 \%$ ).

\section{HANDLING OF BAL FLUID}

Cells were pelleted at $400 \mathrm{~g}$ for five minutes at $4{ }^{\circ} \mathrm{C}$ and resuspended in $5 \mathrm{ml}$ of Hank's solution. A total cell count was carried out in a Bürker chamber and a differential cell count on cytocentrifugal smears prepared in a Cytospin 2 apparatus (Shandon, Southern Products Ltd, Runcorn, England) at $500 \mathrm{rev} / \mathrm{min}$ for three minutes. Cells were stained by the May-Grünwald Giemsa method, and 500 cells were counted. The supernatant was stored at $-70^{\circ} \mathrm{C}$ until analysis.

\section{BIOCHEMICAL ANALYSES IN BAL FLUID}

Albumin concentration was determined by rocket immunoelectrophoresis. ${ }^{11}$ Rat albumin and rabbit anti-rat albumin antibodies (Nordic Immunochemical Lab, Tilburg, The Netherlands) were used as standard and antiserum respectively.

Fibronectin was assayed by a double sandwich enzyme linked immunosorbent assay. ${ }^{12}$ Serum fibronectin of nephelometric quality from BehringHoechst (Frankfurt am Main, Germany) was used as standard. Because human fibronectin and antibodies against the human antigen were used, the BAL fluid concentrations of fibronectin in the rat may not be true values. They are, however, well suited for comparing fibronectin concentrations in alumina exposed and control rats.

Hyaluronan was analysed in principle according to Engström-Laurent ${ }^{13}$ with the Pharmacia HA test kit (Pharmacia, Uppsala, Sweden). Because human antigen was used, the limitations are the same as for fibronectin.

\section{HISTOLOGY}

From five animals in each time and treatment group pieces were taken from three different levels of the right lower lobe of the lung for histological investigation. The tissue was fixed in $10 \%$ neutral formaldehyde and embedded in paraffin. The sections were stained with haematoxylin eosin and examined by light microscopy.

\section{STATISTICS}

Comparisons were only made between control and alumina exposed groups and always with the same follow up time. The statistical significance of differences was analysed by Student's $t$ test.

\section{Results \\ HISTOLOGICAL FINDINGS IN THE LUNG}

The histological sections of lungs from control animals and those exposed to PA or SA did not differ at any time point. Thus no signs of fibrosis were found in any of the animals. 
Table 1 Concentrations of cells (cells $\times 10^{6}$ per litre) in BAL fluid one, four, and 12 months after the intratracheal installation of saline $(C)$, primary alumina $(P A)$, or fluoride-adhered secondary alumina $(S A)$

\begin{tabular}{|c|c|c|c|c|c|c|c|c|c|}
\hline & \multicolumn{3}{|l|}{ One month } & \multicolumn{3}{|c|}{ Four months } & \multicolumn{3}{|l|}{12 months } \\
\hline & $C(n=5)$ & $P A(n=7)$ & $S A(n=7)$ & $C(n=5)$ & $P A(n=7)$ & $S A(n=7)$ & $C(n=7)$ & $P A(n=7$ & ) $S A(n=7)$ \\
\hline $\begin{array}{l}\text { Total cells } \\
\text { Macrophages } \\
\text { Lymphocytes } \\
\text { Neutrophils }\end{array}$ & $\begin{array}{c}79.6(34.7) \\
76.4(34.5) \\
2 \cdot 4(0.9) \\
0.8(0.8)\end{array}$ & $\begin{array}{c}82.3(14.7) \\
80.5(14.7) \\
0.9(0.3)^{\star \star} \\
0.6(0.9)\end{array}$ & $\begin{array}{c}139 \cdot 6(39 \cdot 4)^{\star} \\
128 \cdot 4(37 \cdot 2)^{\star} \\
2.9(2 \cdot 4) \\
7 \cdot 9(4 \cdot 2)^{\star \star}\end{array}$ & $\begin{array}{c}93.6(41.8) \\
91.8(40.4) \\
1.8(1.9) \\
0.1(0.0)\end{array}$ & $\begin{array}{c}75.0(23.7) \\
73.6(23.9) \\
1.2(1 \cdot 2) \\
0.2(0.3)\end{array}$ & $\begin{array}{c}88 \cdot 1(41 \cdot 8) \\
85.4(41 \cdot 2) \\
1.7(1 \cdot 5) \\
1 \cdot 1(1 \cdot 1)\end{array}$ & $\begin{array}{c}53.1(19.8) \\
52.3(19.8) \\
0.4(0.8) \\
0.3(0.5)\end{array}$ & $\begin{array}{c}55.5(11.5) \\
54.4(11.8) \\
0.7(0.7) \\
0.3(0.5)\end{array}$ & $\begin{array}{c}93.3(39.1)^{\star} \\
90.8(38.8)^{\star} \\
0.8(0.5) \\
1.6(0.9)^{\star \star}\end{array}$ \\
\hline
\end{tabular}

Values are mean (SD).

${ }^{\star} \mathrm{p}<0.05 ;{ }^{\star \star} \mathrm{p}<0.01$ for difference from $\mathrm{C}$.

\section{CELLULAR BAL FLUID COMPONENTS}

The mean total number of cells recovered by BAL in control and PA exposed rats was between two and four million, and the mean total cell concentration between 50 and 80 million cells/1. Compared with controls, PA treated rats showed no significant increase either in total numbers or concentrations of cells at any time. Nor were there any significant changes in concentrations of the various cell populations, except for a lower $(p<0.05)$ concentration of lymphocytes one month after exposure (table 1 ).

By contrast, SA treated rats showed a significantly $(p<0.05)$ increased total cell concentration one month and 12 months after exposure (table 1). The increase in BAL fluid cells of SA treated rats was mainly caused by significantly $(p<0.05)$ increased macrophage concentrations after one and 12 months. There were, however, no significant changes in the percentages of macrophages (data not shown) or the concentrations or percentages of lymphocytes in SA treated rats (table 1). By contrast, a significant ( $p<0.01$ ) eightfold and fivefold increase in neutrophils were found in SA treated rats one month and one year after exposure (table 1).

\section{SOLUBLE BAL FLUID COMPONENTS}

Compared with controls, neither PA nor SA treated rats showed significant changes in the concentrations of albumin and hyaluronan with the exception of slightly lower $(p<0.05)$ albumin concentration in PA treated rats four months after exposure. One year after exposure both PA and SA treated rats had highly significant $(p<0.001)$ raised concentrations of fibronectin (table 2).

\section{Discussion}

Except for a slight decrease in lymphocyte concentration one month after instillation of PA no significant changes in alveolar cell concentrations or in alveolar capillary permeability were found one to 12 months after exposure. This is in accordance with earlier lavage studies, which showed that the cellular response appears within a few days after exposure and returns to normal within one to two months. ${ }^{6714} \mathrm{By}$ contrast, rats exposed to SA showed distinct changes in their alveolar environment. There were significant increases in total cell, macrophage and neutrophil concentrations one and $\mathbf{1 2}$ months after the instillation, but no signs of changed alveolar capillary permeability. The findings indicate a persistent alveolitis of low intensity.

As increased cell concentrations were only found in the SA treated animals, the exposure to fluoride is considered to be essential. The prevalence of acute and chronic pulmonary complaints has also been reported to be higher after exposure to "fluoride recovery alumina" than to pure alumina. ${ }^{4} \mathrm{~A}$ possible pathogenetic mechanism may be phagocytosis of alumina with adhered fluoride by macrophages, followed by the release of chemotactic substances for neutrophils. ${ }^{14}$ Neutrophils in turn could play an important part in damage to lung tissue through the release of proteolytic enzymes and free oxygen radicals. In experimental studies, emphysema with

Table 2 Concentrations of albumin ( $\mathrm{mg} / \mathrm{l})$, fibronectin $(\mu \mathrm{g} / \mathrm{l})$, and hyaluronan $(\mu \mathrm{g} / \mathrm{l})$ in $B$ AL fluid one, four, and 12 months after the intratracheal installation of saline $(C)$, primary alumina $(P A)$ or fluoride-adhered secondary alumina $(S A)$

\begin{tabular}{|c|c|c|c|c|c|c|c|c|}
\hline & \multicolumn{3}{|l|}{ One month } & \multicolumn{3}{|l|}{ Four months } & \multicolumn{2}{|l|}{12 months } \\
\hline & $C(n=5)$ & $P A(n=7)$ & $S A(n=7)$ & $C(n=5)$ & $P A(n=7)$ & $S A(n=7)$ & $C(n=7)$ & $P A(n=7) \quad S A(n=7)$ \\
\hline $\begin{array}{l}\text { Albumin } \\
\text { Fibronectin } \\
\text { Hyaluronan }\end{array}$ & $\begin{array}{l}28 \cdot 0(4 \cdot 6) \\
30 \cdot 4(4 \cdot 9) \\
11 \cdot 1(2 \cdot 3)\end{array}$ & $\begin{array}{l}20 \cdot 2(8 \cdot 9) \\
29 \cdot 3(4 \cdot 4) \\
10 \cdot 1(1 \cdot 4)\end{array}$ & $\begin{array}{l}37.7(16 \cdot 2) \\
59 \cdot 0(29 \cdot 5) \\
11.3(1.5)\end{array}$ & $\begin{array}{l}25 \cdot 6(6 \cdot 6) \\
26 \cdot 5(2 \cdot 1) \\
12 \cdot 2(3 \cdot 0)\end{array}$ & $\begin{array}{l}17.9(3 \cdot 8)^{\star} \\
27 \cdot 8(4 \cdot 9) \\
13.7(1.3)\end{array}$ & $\begin{array}{l}22 \cdot 3(7 \cdot 3) \\
32 \cdot 9(11 \cdot 7) \\
15 \cdot 4(2 \cdot 6)\end{array}$ & $\begin{array}{r}17 \cdot 4(5 \cdot 5) \\
21 \cdot 7(1 \cdot 2) \\
9 \cdot 6(2 \cdot 6)\end{array}$ & $\begin{array}{ll}22 \cdot 7(12 \cdot 4) & 20 \cdot 9(4 \cdot 5) \\
40 \cdot 2(7 \cdot 5)^{\star \star \star} & 43 \cdot 9(12 \cdot 4)^{\star \star} \\
10 \cdot 4(1.5) & 10 \cdot 3(1.5)\end{array}$ \\
\hline
\end{tabular}

Values are mean $(\mathrm{SD})$.

${ }^{\star} p<0.05 ;{ }^{\star \star \star} p<0.001$ for differences from $C$. 
damaged bronchial epithelium and interalveolar septa was reported after exposure to hydrogen fluoride, ${ }^{15}$ and alveolar haemorrhagic necrosis with oedema followed by hyperplasia of alveolar cells and loss of alveolar architecture was found after subcutaneous injections of sodium fluoride. ${ }^{16}$

The most striking finding and, to our knowledge, the first such report, was the increase in BAL fluid fibronectin. Fibronectin concentration was increased one and 12 months after instillation in SA exposed rats, and 12 months after exposure in PA treated animals. Thus it is concluded that alumina and not fluoride is essential for the increase in fibronectin concentration. Earlier we reported that aluminium potroom workers have increased fibronectin concentrations in BAL fluid. ${ }^{9}$ Fibronectin is known to be produced in alveolar macrophages. ${ }^{17}$ Although the macrophage concentration was not increased in PA exposed animals 12 months after exposure, the concentration of fibronectin was increased. Thus other cell types such as epithelial cells or fibroblasts have to be considered as possible sources of fibronectin. Fibronectin is a multifunctional glycoprotein, able to opsonise alveolar debris for phagocytosis, to attract neutrophils and fibroblasts, and stimulate fibroblast growth $\left(\mathrm{see}^{18}\right)$. Due to its many binding sites for fibrin, ${ }^{19}$ glycosaminoglycans, ${ }^{20}$ and collagen, ${ }^{21}$ it may contribute to the build up of an extracellular matrix network. The present finding of progressively increasing concentrations of fibronectin in BAL fluid after exposure to alumina suggests that fibronectin may play an active, possibly even central part in the inflammatory reaction. This process may help with repair but when in excess it may lead to fibrosis.

There were no signs of pulmonary fibrosis in any of the animals. Physiochemical properties of the alumina dust are important for their fibrogenic effects on the lungs. ${ }^{5}$ In our present study, the particle size was larger and the surface area was smaller than in those alumina dusts that have been earlier shown to induce pulmonary fibrosis in experimental animals. ${ }^{5}$

Although the non-physiological route of administration used in this study possibly causes a pulmonary overload, the results indicate the need for investigations to evaluate the effects of repeated and prolonged exposure by inhalation.

We thank Roine Hernbrand and Barbro Larsson, Karolinska Hospital, for excellent technical assistance. Wubeshet Sahle and Gun-Britt Berglund, Division of Aerosols at the National Institute of Occupational Health, Solna are gratefully acknowledged for analysis and description of the alumina samples. Grants were received from the Swedish Work Environment Fund, the Swedish Heart Lung Foundation, and the research funds of the Karolinska Institute.
Requests for reprints to: Göran Tornling, MD, Department of Thoracic Medicine, Karolinska Hospital, S-104 01 Stockholm, Sweden.

1 Abramson MJ, Wlodarczyk JH, Saunders NA, Hensley MJ. Does aluminium smelting cause lung disease? Am Rev Respir Dis 1989;139:1042-57.

2 Chan-Yeung M, Enarson DA, MacLean L, Irving D. Longitudinal study of workers in an aluminium smelter. Arch Environ Health 1989;44:134-9.

3 Larsson K, Eklund A, Arns R, Löwgren H, Nyström J, Sundström $G$, Tornling $G$. Lung function and bronchial reactivity in aluminum potroom workers. Scand $J$ Work Environ Health 1989;15:296-301.

$4 \mathrm{Lie} A$, Eduard $W$. The influence of fluoride recovery alumina on the work environment and the health of aluminium potroom workers. Med Lav 1981;72:313-7.

5 Dinman BD. Alumina-related pulmonary disease. J Occup Med 1988;30:328-35.

6 Fritsch P, Masse R, Stanislas G, Chrétien J. Etude dynamique comparative de la population cellulaire intra-alvéolaire après injection intratrachéale d'hydroxyde de beryllium et d'hydroxide d'aluminium chez le rat. Biomedicine 1975;23: 97-102.

7 Lindenschmidt RC, Driscoll KE, Perkins MA, Higgins JM, Maurer JK, Belfiore KA. The comparison of a fibrogenic and two non-fibrogenic dusts by bronchoalveolar lavage. Toxicol Appl Pharmacol 1990;102:268-81.

8 Badenoch-Jones P, Turk JL, Parker D. The effect of some aluminium and zirconium compounds on guinea-pig peritoneal macrophages and skin fibroblasts in culture. J Pathol 1978;124:51-61.

9 Eklund A, Arns R, Blaschke E, et al. Characteristics of alveolar cells and soluble components in bronchoalveolar lavage fluid from non-smoking aluminium potroom workers. $\mathrm{Br} J$ Ind $\mathrm{Med}$ 1989;46:782-6.

10 Eklund A, Tornling G, Blaschke E, Curstedt T. Extracellular matrix components in bronchoalveolar lavage fluid in quartz exposed rats. Br J Ind Med 1991;48:776-82.

11 Laurell C-B. Electroimmunoassay. Scand J Clin Lab Invest 1972;29(suppl 124):21-37.

12 Blaschke E, Eklund A, Hernbrand R. Determination of fibronectin and its degradation products in bronchoalveolar lavage fluid. Scand J Clin Lab Invest 1990;50:619-25.

13 Engström-Laurent A, Laurent UB, Lilja K, Laurent TC. Concentration of sodium hyaluronate in serum. Scand J Clin Lab Invest 1985;45:497-504.

14 Rylander R, Siöstrand M, Bergström R. Free lung cell response after combined exposure to cigarette smoke and industrial dusts. Toxicology 1979;12:211-20.

15 Humiczewska M, Kuzna W, Put A. Studies on the toxicology of fluorine compounds. I. Historical and histochemical investigations on the liver, heart, lungs, and stomach of rats exposed to hydrogen fluoride. Folia Biol 1989;37:181-6.

16 Shashi, Thapar SP, Singh JP. Pulmonary damage caused by fluoride in rabbits during experimental fluorosis. APMIS 1988;96:333-6.

17 Rennard SI, Hunninghake GW, Bitterman PB, Crystal RG. Production of fibronectin by the human alveolar macrophage: mechanism for the recruitment of fibroblasts to sites of tissue injury in interstital lung diseases. Proc Natl Acad Sci USA 1981;78:7147-51.

18 Blaschke E, Eklund A, Hernbrand R. Extracellular matrix components in bronchoalveolar lavage fluid in sarcoidosis and their relationship to signs of alveolitis. Am Rev Respir Dis 1990;141:1020-25.

19 Procyk R, Adamson L, Block M, Blombäck B. Factor XIII catalyzed formation of fibrinogen-fibronectin oligomers-a thiol enhanced process. Thromb Res 1985;40:833-52.

20 Yamagata M, Yamada KM, Yoneda M, Suzuki S, Kimata K. Chondroitin sulfate proteoglycan (PG-M-like proteoglycan) is involved in the binding of hyaluronic acid to cellular fibronectin. J Biol Chem 1986;261:13526-35.

21 Ruoslahti E, Engvall E. Complexing of fibronectin, glycosaminoglycans and collagen. Biochem Biophys Acta 1980;631:350-8.

Accepted 30 March 1992 